\title{
A AVALIAÇÃO NOS ANOS INICIAIS DO ENSINO FUNDAMENTAL: UM RETRATO DA PRÁTICA DOS PROFESSORES DE EDUCAÇÃO FÍSICA NA REDE PÚBLICA MUNICIPAL DE CUIABÁ
}

\author{
Fábio Ferreira da Silva \\ Centro Universitário Várzea Grande, Várzea Grande, Mato Grosso, Brasil \\ Sarah Emanuelle Wanderlei Barbosa de Moura \\ Centro Universitário Várzea Grande, Várzea Grande, Mato Grosso, Brasil \\ Raquel Stoilov Pereira \\ Centro Universitário Várzea Grande, Várzea Grande, Mato Grosso, Brasil
}

\begin{abstract}
Resumo
Esta pesquisa do tipo descritiva com abordagem qualitativa buscou investigar a compreensão dos professores de Educação Física da rede pública municipal de Cuiabá em relação à avaliação da aprendizagem. Ocorreu em 52 escolas, com a participação de 92 professores dos anos iniciais do Ensino Fundamental. A partir do questionário adotado identificamos que embora $66 \%$ dos professores entendam o ato de avaliar como algo fácil e $75 \%$ reconheçam que os conhecimentos adquiridos durante a graduação foram suficientes ou parcialmente suficientes, há equívocos em relação ao conceito e função atribuídos a avaliação. Constatamos um engessamento por parte da Secretaria de Educação de Cuiabá em relação aos descritores de avaliação, culminando apenas no cumprimento de uma tarefa burocrática.
\end{abstract}

Palavras-chave: Avaliação. Docentes. Educação Física e Formação Continuada.

\section{Introdução}

A avaliação é um elemento sempre presente nas ações humanas, uma vez que constantemente os sujeitos precisam decidir-se diante de diferentes situações postas, a partir do que compreendem ser correto. De acordo com Pereira e Moreira (2011, p. 271):

\begin{abstract}
A palavra avaliação está repleta de significados, na maioria das vezes, não muito agradáveis. Quando ouvimos expressões do tipo "Amanhã você será avaliado!" ou "Sua avaliação não foi muito boa!", parece que nosso corpo é tomado por um imenso pavor. Não importa o tipo de avaliação que façamos (fazer a prova da escola de inglês; responder ao questionário de língua portuguesa; executar a manchete no jogo de vôlei; cozinhar pela primeira vez para o esposo e a família dele), pois a palavra avaliação, por si só carrega todo esse estigma, ou melhor, todo esse "desespero".
\end{abstract}

Estudar a temática "avaliação na educação física escolar" se faz relevante na medida em que, de acordo com Hoffmann (2003), muitas vezes os professores compreendem a avaliação como 
uma simples decisão em aprovar ou reprovar os alunos, ou seja, uma ação meramente burocrática, em que são obrigados a exercê-la da forma mais rígida e no menor tempo possível, sem a percepção da relevância e da função da avaliação na escola, com relação à aprendizagem do aluno. Afinal de contas, existem outros conteúdos a serem trabalhados e não é possível "perder tempo" com um mesmo conteúdo até que os alunos tenham êxito na avaliação, mesmo porque, há um tempo de ensinar, um tempo de aprender, um tempo de provar.

Mas antes de discutirmos as questões voltadas a avaliação no ambiente escolar, faz-se necessário compreender a palavra avaliação. De acordo com Luckesi (2014a) o termo "avaliação" deriva do latim "a" e "valere", que associados significam "atribuir valor a alguma coisa, no caso, conferir qualidade a algo que foi realizado". Por sua vez, Wachowicz (2006) define avaliar a partir do prefixo da ortografia "a" significando não e "valiar" atribuir valor, ou seja, não valorar. Ao analisarmos com profundidade a ideia dos autores, entendemos que partilham da mesma ideia, pois admitem que a aprendizagem por ser um fenômeno, torna-se complexa, sendo impossível atribuí-la um valor, visto que é um processo contínuo.

A falta de compreensão sobre a avaliação culmina em alguns equívocos, especialmente quando as pessoas, inclusive alunos e professores que convivem de maneira próxima com a avaliação, entendem que essa esteja relacionada exclusivamente a notas, conceitos, boletim, recuperação, aprovação e, é claro, a provas (HOFFMANN, 2005). Essa dificuldade amplia-se quando os professores não sabem como e o que fazer para mudar, pois apenas ouviram falar, mas faltam-lhes conhecimentos e ferramentas para por em prática, ou mesmo, quando ainda não perceberam a necessidade da mudança, pois sentem-se a par desse processo. (VASCONCELLOS, 2005). Luckesi (2014b) esclarece bem essa questão, ao afirmar que a atribuição de notas e conceitos refere-se apenas ao registro de resultados e não a avaliação em si.

Hoffmann (2005, p. 46, grifos da autora) complementa tal consideração ao afirmar:

Julgo que conceber e nomear o "fazer testes", o "dar notas", por avaliação é uma atitude
simplista e ingênua! Significa reduzir o processo avaliativo, de acompanhamento e ação
com base na reflexão, a parcos instrumentos auxiliares desse processo, como se
nomeássemos por bisturi um procedimento cirúrgico.

No entanto, a avaliação precisa ser definida, discutida, refletida e transformada coletivamente, num processo de paridade entre professor e aluno o que, naturalmente, corresponde a uma tarefa complexa e contínua. Nesse sentido, pesquisas relacionadas a essa temática se fazem cada vez mais necessárias na intenção de melhor compreender o cotidiano escolar, com vistas a qualificar a prática docente, afinal, Krasilchik (2002) afirma que a avaliação oferece, ao docente, informações, dados, sobre o processo de ensino, permitindo a identificação das falhas, por que elas ocorreram, possibilitando que sejam retomadas e reconsideradas.

Nesse sentido, a avaliação não deve "verificar o que o aluno absorveu do conteúdo", mas deve proporcionar clareza tanto para o professor quanto para o aluno, em relação à aprendizagem alcançada. (OLIVEIRA, 2009, p. 66). No entanto, Sant'Anna (1995) ressalta que raramente os alunos são informados sobre a função da avaliação, de maneira a serem capazes de conhecer e compreender seus verdadeiros objetivos e intenções.

Melo (2011) identificou nos discursos dos professores que a avaliação é realizada sem compromisso, crítica ou reflexão, repercutindo, diretamente na qualidade dessas aulas. 
A avaliação deve estar intimamente relacionada com o objetivo ao qual se pretende alcançar, pois de acordo com Luckesi (2014c) a avaliação serve à ação, e esta corresponde ao alcance dos objetivos. Para tanto, a avaliação inicia-se na construção do Projeto Político Pedagógico (PPP), o qual representa a identidade da escola e que indica meios de se alcançar um ensino de qualidade.

Os professores têm cometido alguns equívocos com relação à avaliação, dentre eles: utilizar a avaliação como punição para alguns alunos e prêmios para outros; confiar totalmente no seu "olhar clínico" e deixar de lado as verificações parciais no processo de ensino e aprendizagem; dispensar o método quantitativo e valorizar somente o qualitativo, uma vez visto que, a avaliação consiste no uso de ambas as partes. (LIBÂNEO, 1994).

Assim, Hoffmann (1998) pressupõe que a mudança desse pensamento está atrelada a um processo de formação docente no que se refere às concepções em avaliação educacional, mesmo porque, Bermudes e Ost (2013) e Melo, Ferraz e Nista-Piccolo (2010) concordam que a graduação proporciona somente o básico para o professor, e que não sustenta o processo reflexivo ativo na ação pedagógica, pois seu espaço de tempo é curto.

Essa falta de compreensão justifica algumas práticas apresentadas por professores, que comumente avaliam a partir das experiências que tiveram quando alunos, num processo de imitação dos procedimentos que julgavam interessantes, sem ao menos se perguntarem se correspondem a processos adequados, ou não. (LUCKESI, 2014d).

Em específico, no caso da Educação Física, também identificamos essa reprodução de avaliação a partir das experiências enquanto aluno, tais como mencionam Pereira e Moreira (2011): de acordo com a presença do aluno; estar devidamente uniformizado para as aulas; comportamento; aplicação de testes físicos/ motores; provas práticas visando performance e estereotipação; aplicação de provas em que é cobrada a memorização de regras ou história de determinada modalidade.

Hoffmann (2001, p. 13, grifos da autora) enfatiza que: O grande dilema é que não há como “ensinar melhores fazeres de avaliação". Esse caminho precisa ser construído por cada um de nós, pelo confronto de idéias (sic.), repensando e discutindo, em conjunto, valores, princípios e metodologias.

Assim, o objetivo da pesquisa foi investigar a compreensão dos professores de Educação Física da rede pública municipal de Cuiabá em relação à avaliação da aprendizagem.

\section{Metodologia da pesquisa}

O presente estudo caracteriza-se como uma pesquisa descritiva, pois: “[...] observa, registra, analisa e correlaciona fatos ou fenômenos (variáveis) sem manipulá-lo; [além disso], procura descobrir, com a precisão possível, a freqüência (sic.) com que um fenômeno ocorre, sua relação e conexão com outros, sua natureza e características."(CERVO; BERVIAN,1996, p. 49). A pesquisa adota como método à abordagem qualitativa, visto que não tem como intenção numerar ou medir durante a análise do problema. (OLIVEIRA, 2000).

Em um primeiro momento realizamos o levantamento de referenciais teóricos sobre a avaliação e a educação física escolar que sustém a análise e interpretação dos dados coletados junto aos sujeitos da pesquisa. 
Buscando o maior número de professores, adotamos a estratégia inicial de participarmos dos encontros mensais, a chamada "roda de conversa". Esses encontros ocorrem, geralmente, na última sexta-feira de cada mês, em que, um grupo de pesquisadores de instituições de ensino superior privada e pública de cursos de Educação Física reúnem-se a esses professores para tratarem da matriz curricular para o ensino da Educação Física nas escolas da rede pública municipal de Cuiabá. A matriz foi elaborada conjuntamente, a partir de uma relação dialógica entre os professores pesquisadores e professores da rede, com o intuito de nortear o trabalho dos professores de Educação Física e melhorar a ação docente e qualidade das aulas, baseando-se nas experiências declaradas desses docentes, sem a adoção de referencias didático-metodológicos específicos. Inicialmente diagnosticaram a realidade das escolas da rede (potencialidades e dificuldades) e depois elencaram objetivos, conteúdos e respectivas cargas horárias, pensando em 80 aulas no ano e, por fim, possibilidades de avaliação.

Participamos de dois desses encontros quando 48 professores responderam ao questionário. Todos os docentes presentes foram consultados, mas muitos não se interessaram em participar. Também visitamos as escolas, com o intuito de ampliar o número de professores participantes, sendo que ao total chegamos a 92 docentes (que em média, têm 36 anos, atuam a 10 anos como professor de Educação Física na Educação Básica e a 08 anos na rede pública municipal de Cuiabá) de 52 escolas, correspondente a $65,8 \%$ do total de escolas urbanas da rede.

Nesses dias dos encontros e das idas às escolas, entregamos aos docentes uma carta de apresentação, o Termo de Consentimento Livre e Esclarecido (TCLE) em duas vias e o instrumento de pesquisa que corresponde a um questionário dividido em levantamento do perfil docente e 11 questões voltadas a avaliação da aprendizagem.

O questionário foi elaborado de acordo com as informações que os pesquisadores entendiam necessárias para o alcance dos objetivos almejados sem, contudo, pautar-nos em instrumentos validados anteriormente. Importante ressaltar que buscando garantir a clareza das questões elaboradas, realizamos um estudo piloto com a aplicação do questionário a 5 professores da rede pública municipal de Cuiabá que atuam com a Educação Infantil. afirma que:

Optamos por analisar os dados a partir da categorização das respostas. Gil (2008, p. 157)

As respostas fornecidas pelos elementos pesquisados tendem a ser as mais variadas. Para que essas respostas possam ser adequadamente analisadas, torna-se necessário, portanto, organizá-las, o que é feito mediante o seu agrupamento em certo número de categorias.

De acordo com o autor, esse processo de definição de categorias deve considerar dois princípios importantes: o número de categorias criadas deve ser suficiente para incluir todas as respostas identificadas e uma categoria não pode estar dentro de outra, assim, se for o caso essas categorias devem juntar-se para formar outra categoria. Caso isso ocorra, o processo de categorização deve ser revisto. Nesse sentido, o número de categorias variou de acordo com o agrupamento de respostas realizado pelos pesquisadores.

\section{Apresentação e interpretação dos dados}

Buscando melhor compreensão dos dados coletados, apresentaremos e discutiremos questão a questão, com o intuito de responder ao objetivo do presente estudo que foi investigar a 
compreensão dos professores de Educação Física da rede pública municipal de Cuiabá em relação à avaliação da aprendizagem, sem preocuparmo-nos com a comparação entre um professor e outro ou entre uma escola e outra, buscando apresentar um panorama geral da realidade estudada.

$\mathrm{Na}$ questão 1 perguntamos aos professores: "Para você, o que é avaliação da aprendizagem?". Por ser uma pergunta aberta, categorizamos as respostas e identificamos duas categorias, sendo que dois professores não responderam a questão.

\begin{tabular}{l|c}
\hline \multicolumn{1}{c|}{ MANIFESTAÇÕES DOS PROFESSORES } & FREQUENCIA (\%) \\
\hline É o processo que visa obter o conhecimento/entendimento do aluno & $90 \%$ \\
É julgar se os objetivos foram alcançados & $10 \%$ \\
\hline
\end{tabular}

TABELA 1 - Definição da avaliação da aprendizagem, na concepção dos professores.

Entendemos que de certa forma os professores se aproximam do conceito de avaliação defendido por Libâneo (1994), ou seja, verificar juntamente com os alunos se os objetivos propostos foram alcançados. No entanto, ao aprofundarmos a análise fica a dúvida se os professores conseguem relacionar a avaliação com os objetivos de ensino. Temos a impressão de que o conceito defendido pelos professores aproxima-se muito mais de um simples diagnóstico dos saberes do que da verificação de todo o processo de aprendizagem.

Na questão 2 indagamos: "Para você, qual a função da avaliação nas aulas de educação física? Explique”.

\section{MANIFESTAÇÕES DOS PROFESSORES}

FREQUÊNCIA (\%)

Realizar as intervenções necessárias, servindo também como diagnóstico para novos planejamentos

Acompanhar o desenvolvimento de cada aluno na aprendizagem

Identificar o nível de desenvolvimento motor do aluno

Verificar se o conteúdo desenvolvido está adequado

Identificar o nível de desenvolvimento cognitivo do aluno

Identificar o nível de desenvolvimento afetivo social do aluno

$57 \%$

$22 \%$

$09 \%$

$04 \%$

$04 \%$

$04 \%$

TABELA 2 - Função da avaliação nas aulas de Educação Física.

Esses dados reforçam as considerações apresentadas na questão 1, ou seja, a forte relação da avaliação da aprendizagem com o diagnóstico. Sant'Anna (1998) afirma que a Avaliação Diagnóstica tem o objetivo de mostrar ao aluno e professor como está o processo de ensinoaprendizagem. Busca, portanto, verificar se o aluno realmente está aprendendo, ou mesmo identificar o nível de conhecimento em relação ao assunto ou habilidade que se deseja desenvolver.

Assim, o diagnóstico é fundamental (LIBÂNEO, 1994), mas também precisamos ir além, pois se pararmos no diagnóstico nossa análise será superficial.

Além disso, verificamos certa confusão por parte dos professores em relação ao conceito e função da avaliação. Por repetidas vezes os professores apresentaram a mesma resposta nas questões 1 e 2. De acordo com Hoffmann (1998) isso acontece, porque, muitas vezes, os professores desconhecem o verdadeiro sentido do ato de avaliar.

Na questão 3 ao perguntarmos: "Você avalia seus alunos nas aulas de Educação Física? Por que?". Quatro professores não responderam a essa questão, deixando-a em branco. Entre as justificativas apresentadas pelos professores que responderam Sim, identificamos duas categorias. 


\begin{tabular}{l|c}
\hline \multicolumn{1}{c|}{ MANIFESTAÇÕES DOS PROFESSORES } & FREQUENCIA (\%) \\
\hline Para diagnosticar o aprendizado do aluno & $72 \%$ \\
Repensar a metodologia e material pedagógico & $28 \%$ \\
\hline
\end{tabular}

TABELA 3 - Justificativas dos professores que responderam que avaliam seus alunos.

A partir desses dados a relação entre diagnóstico e avaliação fica ainda mais evidente, como já discutido nas questões 1 e 2 .

Na questão 4: "Qual(is) instrumento(s) de avaliação você utiliza? Cite-o(s)". Identificamos 13 categorias, sendo que dois professores não responderam a questão.

\begin{tabular}{l|c}
\hline \multicolumn{1}{c|}{ MANIFESTAÇÕES DOS PROFESSORES } & FREQUENCIA (\%) \\
\hline Observação assistemática & $16 \%$ \\
Observação da participação nas aulas & $15 \%$ \\
Relatório & $15 \%$ \\
Observação do desenvolvimento motor & $12 \%$ \\
Prova escrita & $10 \%$ \\
Prova prática & $08 \%$ \\
Observação das dificuldades dos alunos & $06 \%$ \\
Ficha de avaliação & $05 \%$ \\
Roda de conversa & $04 \%$ \\
Trabalho escrito & $04 \%$ \\
Através de desenhos & $02 \%$ \\
Questionário & $02 \%$ \\
Auto-avaliação & $01 \%$ \\
\hline
\end{tabular}

TABELA 4 - Instrumentos de avaliação utilizados nas aulas de Educação Física.

Interessante considerar que os professores pontuam diferentes instrumentos, no entanto, a observação prevalece. Identificamos tanto a observação assistemática (tem como característica a casualidade, ou seja, "olhar por olhar", devido ao fato do professor não estabelecer critérios que nortearão tal observação) como a observação sistemática (o professor define o que será observado e registra, validando as informações para um repensar das futuras aulas). (HAIDT, 1994; DARIDO, 2005). A observação da participação é demasiadamente subjetiva, já que o aluno pode estar de corpo presente, mas não ativo nas atividades. (PEREIRA; MOREIRA, 2011).

O foco deve ser os objetivos traçados. Não há instrumentos corretos ou errados. O que realmente prevalece é a "postura pedagógica", do educador frente aos diversos instrumentos de avaliação. (LUCKESI, 2014b).

Na questão 5 ao perguntarmos: "Você costuma mudar o(s) instrumento(s) de avaliação durante o ano? Justifique". Entre as respostas, 53\% dos professores assinalaram Sim e 47\% Não.

Todos os professores que responderam que mudam os instrumentos de avaliação, o fazem para melhor verificar a aprendizagem da turma/aluno. Nesse sentido, Fernandes (1998 apud Melo, 2011, p. 193) ressalta que:

Se faz necessário diversificar os instrumentos de avaliação em vez de restringir-se a uma única técnica que limita a prática avaliativa a análises restritas de aspectos que interferem no processo avaliativo. Isso significa que o professor deve buscar identificar diferentes 
indicadores que propiciem a compreensão do todo que compõe o processo de ensino, usando diferentes técnicas avaliativas.

Por outro lado, os professores que não mudam os instrumentos de avaliação apresentaram justificativas variadas, apresentadas a seguir:

\begin{tabular}{l|c}
\hline \multicolumn{1}{c|}{ MANIFESTAÇÕES DOS PROFESSORES } & FREQUENCIA (\%) \\
\hline Sigo o PPP da escola & $28 \%$ \\
Não vejo necessidade & $21 \%$ \\
Dificulta a comparação do desenvolvimento/dados & $15 \%$ \\
Sigo o proposto no planejamento anual & $15 \%$ \\
Falta de tempo para conhecer aluno por aluno & $07 \%$ \\
Trabalho com linhas fixas de avaliação & $07 \%$ \\
Utilizo os contidos nos PCN'S & $07 \%$ \\
\hline
\end{tabular}

TABELA 5 - Justificativas dos professores que não mudam os instrumentos de avaliação durante o ano.

Entendemos que os professores não compreendem que os planejamentos anuais e planos de aulas são flexíveis e estão sujeitos a modificações durante o ano letivo, e que isso envolve também a avaliação (LIBÂNEO, 1994). Permanecermos rígidos a avaliação é sermos contrários a questão diagnóstica. Ora, se identificamos nas questões de número 1 a 3 , a forte relação entre avaliação da aprendizagem e diagnóstico, é contraditório os professores não alterarem os instrumentos de avaliação. Se pretendo diagnosticar para, como base nas informações levantadas repensar o processo de ensino, precisamos estar prontos a alterar, inclusive a avaliação, já que ela nos responderá se estamos, ou não, no caminho certo.

Corroboramos com a ideia de Fernandes (1998 apud Melo, 2011, p. 193) de que precisamos sim diversificar os instrumentos de avaliação se pretendemos compreender o processo de ensino-aprendizagem como um todo.

$\mathrm{Na}$ questão 6 indagamos: “O que você avalia em seu aluno?". Identificamos sete categorias e dois professores não responderam a questão.

\section{MANIFESTACÕES DOS PROFESSORES}

FREQUÊNCIA

Habilidades motoras (agilidade, coordenação, equilíbrio, flexibilidade, força, gesto técnico, lateralidade, noção espaçotemporal, peso e altura, ritmo e velocidade)

Habilidades Sociais e afetivas (companheirismo, cooperação, criar laços de amizade, disciplina, liderança, relação professor aluno, respeito e socialização)

Habilidades Cognitivas (atenção, autocontrole, autoestima, autonomia, concentração, criatividade, organização, responsabilidade, solução de situações-problemas e tomada de atitude)

Participação e interesse nas aulas

Frequência e pontualidade

Conhecimento do corpo e seus limites

Estar com vestimenta adequada para as aulas

$27,5 \%$

$13,7 \%$

$12,7 \%$

$2,9 \%$

$0,4 \%$

$0,4 \%$

TABELA 6 - O que os professores avaliam em seus alunos.

As questões voltadas às habilidades motoras ainda são vistas com relevância pelos professores, remetendo-nos a compreensão de que há certo predomínio motor nas aulas de Educação Física, distanciando-se da compreensão do aluno como sujeito integral. 
Ao pensarmos na participação e interesse nas aulas caímos em situações muito subjetivas e complexas para aferir, reforçando os resultados encontrados e discutidos na questão 4.

Sobre a frequência e pontualidade Melo (2011, p. 215) considera que: "[...] possa servir como elemento de referência para a tomada de medidas pelo professor e pela escola no sentido de detectar os problemas que estejam dificultando a permanência do aluno nas aulas ou proporcionar novos métodos de ensino". Portanto, podem auxiliar na compreensão de outros elementos, mas não como instrumento de avaliação único.

Em continuidade a pergunta anterior, na questão 7: "Há algum critério para a definição do que será avaliado? Descreva esse(s) critério(s)". Entre as respostas, $1 \%$ dos professores responderam Sim e 19\% Não. No caso da descrição dos critérios, identificamos seis categorias.

\begin{tabular}{l|c}
\hline \multicolumn{1}{c|}{ MANIFESTAÇÕES DOS PROFESSORES } & FREQUÊNCIA \\
\hline De acordo com o objetivo da aula & $40 \%$ \\
De acordo com o conteúdo da aula & $15 \%$ \\
De acordo com o planejamento & $15 \%$ \\
De acordo com a Matriz Curricular de Educação Física da SME de Cuiabá & $15 \%$ \\
De acordo com os critérios da SME (descritores) & $10 \%$ \\
De acordo com o PPP da escola & $05 \%$ \\
\hline
\end{tabular}

TABELA 7 - Descrição dos critérios para a definição do que será avaliado.

Corroboramos com Libâneo (1994) e compreendemos que são os objetivos que definem a avaliação, ou seja, o que e como será avaliado. Assim, causa-nos estranheza os professores que responderam partirem dos conteúdos para definir os critérios de avaliação.

De certo modo, os professores que responderam que partem do PPP da escola e do planejamento, aproximam-se da ideia do autor supracitado, mas apenas oito professores relacionaram, efetivamente, a avaliação aos objetivos.

No caso dos professores que responderam ser de acordo com a matriz curricular (apresentada brevemente na metodologia da pesquisa deste estudo), entendemos como compreensível e positivo, uma vez que se trata de uma elaboração coletiva e vigente. No entanto, poucos foram os relatos, o que merece ser considerado e revisto até para verificar a efetividade da proposta.

Serão analisados juntamente com a questão 11 , todos os professores que responderam estar de acordo com os critérios da SME.

Na questão 8 ao perguntarmos: "Após a avaliação, o que você faz com os dados/ informações/ resultados levantados?". Ao analisarmos as categorias, identificamos quatro grandes grupos:

- avaliação utilizada como diagnóstico para o planejamento futuro (45\%), em que adota a característica da avaliação formativa: consideram os resultados obtidos na avaliação para planejar futuras aulas; elaboram o portfólio/relatório para consultas futuras; criam metodologias para auxiliar os alunos nas suas dificuldades.

- avaliação somativa (13,5\%): analisam e classificam conforme os níveis de aprendizagem; comparam os resultados com outros bimestres.

- avaliação discutida por todos $(11,7 \%)$ : discutem com outros professores; socializam os resultados com os alunos; apresentam e discutem na reunião com os pais. 
- avaliação como cumprimento de tarefa - realiza e arquiva $(29,7 \%)$ : entregam aos coordenadores; registram no sistema da SME; e arquivam.

Entendemos como significativo os professores utilizarem os resultados coletados em situações futuras, mas também que precisamos ir além da simples aferição, como aponta Bento (1998, p. 180) em que a avaliação: "Não se limita a análise do ensino a uma comparação do objetivo e do resultado, a uma análise do rendimento, mas que inclua também a análise das condições determinantes de sucessos e insucessos, de rendimentos e falta de rendimentos".

Da mesma forma, também é interessante os professores que partilham a avaliação com todos os envolvidos no processo, tornando-a coletiva, como sugerido por Hoffman (2005). O ideal seria que essa prática estivesse presente na resposta de todos os professores.

Preocupamo-nos, em demasia, os docentes que adotam apenas uma das situações citadas e aqueles que compreendem a avaliação como ação meramente burocrática. É preciso ir além!

Na questão 9: "Ao avaliar, você se baseia em suas experiências da época em que era aluno na educação básica? Justifique”. No caso, 33\% responderam Sim e 67\% Não.

Todos os professores que responderam basear-se em experiências da época em que eram alunos, justificaram porque o método já está sistematizado, entendendo como método, os instrumentos de avaliação.

Entre os professores que responderam não basear-se nas experiências da época da educação básica, identificamos cinco categorias.

\begin{tabular}{l|c}
\hline \multicolumn{1}{c|}{ MANIFESTAÇÕES DOS PROFESSORES } & FREQUENCIA (\%) \\
\hline São épocas diferentes, com pensamentos e alunos diferentes & $74 \%$ \\
Só jogava futsal e as aulas eram para os mais habilidosos & $11 \%$ \\
Baseia-se no que aprendeu durante a graduação & $09 \%$ \\
Raramente participava das aulas e era avaliado. & $04 \%$ \\
O projeto político pedagógico das escolas são diferentes & $02 \%$ \\
\hline
\end{tabular}

TABELA 8 - Justificativas dos professores que responderam não basear-se em suas experiências da época em que eram alunos da educação básica.

Notamos nessas categorias relatos negativos, como não participar das aulas, ou apenas ter futsal, ou a aula ser para os mais habilidosos. Logo, essas experiências foram determinantes para a conscientização de uma nova prática pedagógica, o que entendemos significativo.

Na questão 10: "Ao avaliar seus alunos nas aulas de Educação Física”, os professores tinham três opções para resposta: você sente dificuldades (34\%), sente facilidades (16\%), realiza essa tarefa como outra qualquer $(50 \%)$.

Chama-nos a atenção o fato de $34 \%$ dos professores reconhecerem que sentem dificuldades no processo avaliativo, o que não é ruim, pois, Romão $(2003$, p. 47) afirma que "Avaliar não é simples e exige domínio de conhecimentos e técnicas, além de experiências em processos concretos de avaliação". Preocupa-nos, no entanto, os 50\% que responderam cumprir essa tarefa como qualquer outra, apesar de apresentarem dificuldades e equívocos ao descreverem conceito, função e instrumentos avaliativos utilizados nas aulas.

Por fim, na questão 11: "Você entende que os conhecimentos oferecidos durante sua graduação em relação à avaliação foram suficientes para o desenvolvimento dessa etapa na intervenção pedagógica", havia três opções para resposta Sim (25\%), Não (21\%), Em partes (54\%). 
Se somarmos os percentuais dos professores que entendem como suficientes os conhecimentos oferecidos durante a graduação com os que responderam ser parcialmente suficiente, chegamos a um total de $75 \%$ dos participantes. Nesse sentido, poderíamos esperar certa compreensão por parte dos professores em relação a conceito e função de avaliação, critérios de definição, escolha dos instrumentos, o que não ocorreu.

Isso nos remete a Bermudes e Ost (2013) e Melo, Ferraz e Nista-Piccolo (2010) quando concordam que a graduação não fornece uma receita pronta de como avaliar. Corroborando com as justificativas de alguns professores eles ainda complementam que os saberes adquiridos pelos professores vêm da prática, durante sua vida profissional, trazendo consigo domínio para exercício, principalmente da avaliação.

Destacamos ainda a resposta de um professor: "A SME já nos manda um tipo de avaliação pronta, basta realizá-la" (PROFESSOR A, ESCOLA 1). Ou seja, o sistema implantado pela SME, é único para toda a rede ${ }^{58}$. Os professores não tem a liberdade de definir o que será ou não avaliado, como apresentado na questão 7. Até porque os descritores apresentados no sistema informatizado não estão de acordo com a matriz curricular implantada. Ou seja, os professores não sabem a que recorrer e acabam preenchendo o sistema apenas para cumprir uma ação burocrática obrigatória em que fica difícil aferir se o professor tem dificuldade ou não nessa ação.

\section{Considerações finais}

Entendemos que atingimos o objetivo da pesquisa que foi investigar a compreensão dos professores de Educação Física da rede pública municipal de Cuiabá em relação à avaliação da aprendizagem.

No caminhar da pesquisa, nos deparamos com certa resistência por parte dos professores em não quererem responder ao questionário, alegando indisponibilidade de tempo.

Todos os professores responderam que avaliam seus alunos na aula de Educação Física, o que é muito positivo. Porém, suas respostas apresentam equívocos e confusões quanto ao conceito e função da avaliação da aprendizagem.

Preocupa-nos o fato da observação ser o instrumento de avaliação mais utilizado nas aulas de Educação Física, já que pode perder-se com o tempo, caso não esteja alinhada ao registro. Da mesma forma, identificamos forte tendência na avaliação de habilidades motoras, afastando-se na compreensão de um sujeito integral que faz, pensa e relaciona-se. Assim, em ambos os casos, os professores precisam ir além de suas práticas, com vistas a melhor compreender seus alunos, quer sejam os avanços, dificuldades, ou mesmo o estágio atual de aprendizagem.

A avaliação está fortemente relacionada com o diagnóstico. Por outro lado, não há consenso na necessidade de alteração dos instrumentos de avaliação ao longo do ano, o que entendemos como incoerente, visto a instabilidade do processo ensino-aprendizagem.

Em relação aos critérios para definição da avaliação, identificamos fragilidade na efetivação da proposta da matriz curricular adotada pela SME de Cuiabá, o que merece novos

\footnotetext{
${ }^{58} \mathrm{O}$ sistema informatizado apresenta os descritores (itens a serem avaliados) e os professores devem apenas assinalar se o aluno construiu, está em construção ou não construiu determinada habilidade. Esses descritores são fixos e não se relacionam com a proposta da matriz curricular da rede.
} 
estudos, bem como na não compreensão dos professores na importância de sempre relacionarem a avaliação aos objetivos de ensino.

Ainda que $66 \%$ dos professores entendam o ato de avaliar como algo fácil e $75 \%$ reconheçam que os conhecimentos adquiridos durante a graduação, em relação a avaliação, foram suficientes ou parcialmente suficientes, no entanto temos dúvidas em relação a esses valores, frente aos equívocos e contradições identificados.

Os resultados não se referem unicamente aos professores, mas a SME como um todo: o engessamento imposto aos professores em relação à avaliação (descritores) carece ser revista; a SME deve promover formações continuadas na área da avaliação da aprendizagem. É preciso definir onde estamos e onde pretendemos chegar, o que, a partir desta pesquisa não está claro, ficando o convite a estudos e propostas futuras.

\title{
EVALUATION OF EARLY ELEMENTARY SCHOOL: A PICTURE OF THE PRACTICE FROM PHYSICAL EDUCATION TEACHERS IN MUNICIAPL PUBLIC SCHOOLS OF CUIABÁ-MT, BRAZIL.
}

\begin{abstract}
This descriptive and qualitative research aimed to investigate the comprehension of Physical Education teachers of the municipal public school in Cuiabá about learning evaluation. The study was carried out in 52 schools, with the participation of 92 early elementary school teachers. From the applied questionnaire we realized that, although $66 \%$ of the teachers understand the act of evaluating anything as easy and $75 \%$ recognize that the knowledge acquired during their graduation was sufficient or partly sufficient, there are misconceptions about the concept and function assigned to evaluation. We found an inflexibility on the part of the Cuiabá Education Department regarding the evaluation descriptors, which culminates only in fulfilling a bureaucratic task.

Keywords: Evaluation. Faculty. Physical Education and continuing education.

\section{LA EVALUACIÓN EN LOS AÑOS INICIALES DE LA ENSEÑANZA FUNDAMENTAL: UN RETRATO DE LA PRÁCTICA DE LOS PROFESORES DE EDUCACIÓN FÍSICA EN LA RED PÚBLICA MUNICIPAL DE CUIABÁ}

\begin{abstract}
Resumen
Esta investigación del tipo descriptiva cualitativa investigó la comprensión de los profesores de Educación Física de la red pública municipal de Cuiabá en relación a la evaluación del aprendizaje. Ocurrió en 52 escuelas, con la participación de 92 profesores de los años iniciales de la Enseñanza Fundamental. A partir de este cuestionario adoptado identificamos que aunque $66 \%$ de los profesores entiendan el acto de evaluar como algo fácil y $75 \%$ reconozcan que los conocimientos adquiridos durante la graduación fueron suficientes o parcialmente suficientes, hay equívocos con relación al concepto y función atribuidos a la evaluación. Constatamos un enyesamiento por parte de la Secretaria de Educación de Cuiabá con relación a los descriptores de evaluación, culminando en el cumplimiento de una tarea burocrática.
\end{abstract}

Palabras-clave: Evaluación. Docentes. Educación Física y Formación Continuada. 


\section{Referências}

BERMUDES, R. F.; OST. M. A. A avaliação em educação física escolar: da mobilização dos saberes à construção das práticas avaliativas para a intervenção pedagógica. Revista Mackenzie de Educação Física e Esporte, v.12, n.1, 2013, p. 95-116.

BENTO, J. O. Análise e avaliação do ensino. In: física. Lisboa: Livros Horizonte, 1998. cap. 8, p. 174-201. . Planejamento e avaliação em educação

CERVO, A. L.; BERVIAN, P. A. Metodologia científica. 4. ed. São Paulo: Makron Books, 1996.

DARIDO, S. C. Avaliação em educação física na escola. In: DARIDO, S. C.; RANGEL. I. C. A. Educação física na escola: implicações para a prática pedagógica. Rio de Janeiro: Guanabara Koogan, 2005. cap. 8, p. 122-136.

GIL, A. C. Métodos e técnicas de pesquisa social. 6. ed. São Paulo: Atlas, 2008.

HAIDT, R. C. C. Avaliação do processo do ensino-aprendizagem. In: Curso de didática geral. São Paulo: Ática, 1994. cap. 13, p. 286-319.

HOFFMANN, J. Avaliação mito \& desafio: uma perspectiva construtivista. 24. ed. Porto Alegre: Mediação, 1998.

. Avaliar para promover: as setas do caminho. Porto Alegre: Mediação, 2001.

Avaliação mediadora: uma prática em construção da pré-escola à universidade. 20. ed. Porto Alegre: Mediação, 2003.

Avaliação mito \& desafio: uma perspectiva construtivista. 35. ed. Porto Alegre: Mediação, 2005.

KRASILCHIK, M. As relações pessoas na escola e a avaliação. In: CASTRO, A. D. de; CARVALHO, A. M. P de. Ensinar a ensinar: didática para a escola fundamental e média. São Paulo: Pioneira Thomson, 2002. cap. 9, p. 165-176.

LIBÂNEO, J. C. A avaliação escolar. In: Didática. São Paulo: Cortez, 1994.

LUCKESI, C. C. Como fica a questão da avaliação "qualitativa" e "quantitativa". Site oficial do professor Cipriano Luckesi. Disponível em: <http://www.luckesi.com.br/pergunda e respostas questao 02.htm>. Acesso em: 06 ago. 2014a.

\begin{tabular}{llcl}
\multicolumn{2}{c}{. Entrevista à revista nova escola sobre avaliação da } & aprendizagem. Site oficial do professor \\
Cipriano & Carlos & Luckesi. & Disponível
\end{tabular} 
〈http://www.luckesi.com.br/textos/art avaliacao/art avalaiacao revista nova escola2001.pdf $>$. Acesso em: 06 ago. 2014b.

A base ética da avaliação da aprendizagem na escola. Disponível em: <http://www.luckesi.com.br/artigosavaliacao.htm>. Acesso em: 06 ago. 2014c.

Avaliação da aprendizagem: visão geral. Entrevista concedida ao Jornalista Paulo Camargo, São Paulo, publicado no caderno do Colégio Uirapuru, Sorocaba, estado de São Paulo, por ocasião da Conferência: Avaliação da Aprendizagem na Escola, Colégio Uirapuru, Sorocaba, SP, 8 de outubro de 2005. Disponível em: <http://www.luckesi.com.br/textos/art_avaliacao/art_avaliacao_entrev_paulo_camargo2005.pdf>. Acesso em: 06 ago. 2014d.

MELO, L. F.; FERRAZ, O. L.; NISTA-PICCOLO, V. L. O portifólio como possibilidade de avaliação na educação física escolar. Revista da Educação Física, Maringá, v. 21, n.1, 2010. p. 8797.

MELO, L. F. Tecendo tramas sobre avaliação da aprendizagem em aulas de

educação física escolar. 2011. 324f. Tese de Doutorado, USJT (Universidade São Judas Tadeu), São Paulo, 2011.

OLIVEIRA, R. C. Avaliação em educação física: concepções e práticas de um professor. Revista Mackenzie de Educação Física e Esporte, v. 8, n. 2, 2009. p. 63-74.

OLIVEIRA, S. L. de. Tratado de metodologia científica: projetos de pesquisa, TGI, TCC, monografias, dissertações e teses. São Paulo: Pioneira, 2000.

PEREIRA, R. S.; MOREIRA, E. C. A difícil tarefa de avaliar: possibilidades na educação física escolar. In: MOREIRA, E. C.; PEREIRA, R. S. (org.). Educação física escolar: desafios e propostas 2. 2. ed. Jundiaí, SP: Fontoura, 2011 cap. 14, p. 271-288.

PERRENOUD, P. Avaliação: da excelência à regulação das aprendizagens - entre duas lógicas. Tradução: Patrícia Chittoni Ramos. Porto Alegre: Artes Médicas Sul, 1999.

ROMÃO, J. E. Avaliação dialógica: desafios e perspectivas. 5 ed. São Paulo: Cortez, 2003.

SANT'ANNA, F. M. et al. A avaliação do ensino-aprendizagem. In: Planejamento de ensino e avaliação. 11. ed. Porto Alegre: Sagra Luzzato, 1998. cap. 7, p. 175-187.

SANT’ANNA, I. M. Por que avaliar? Como avaliar? Petrópolis, RJ: Vozes, 1995.

WACHOWICZ, L. A. Avaliação e aprendizagem. In: VEIGA, I. P. A. (org.). Lições de didática. Campinas, SP: Papirus, 2006. cap. 7, p.135-160. 
Recebido em: 07/08/2014

Revisado em: 02/03/2015

Aprovado em: 10/04/2015

Endereço para correspondência:

Raquel Stoilov Pereira

stoquel@uol.com.br

Av. Dom Orlando Chaves, n. ${ }^{\circ} 2.655$

Bairro Cristo Rei - Várzea Grande

Mato Grosso - Brasil - CEP 78118-900 